
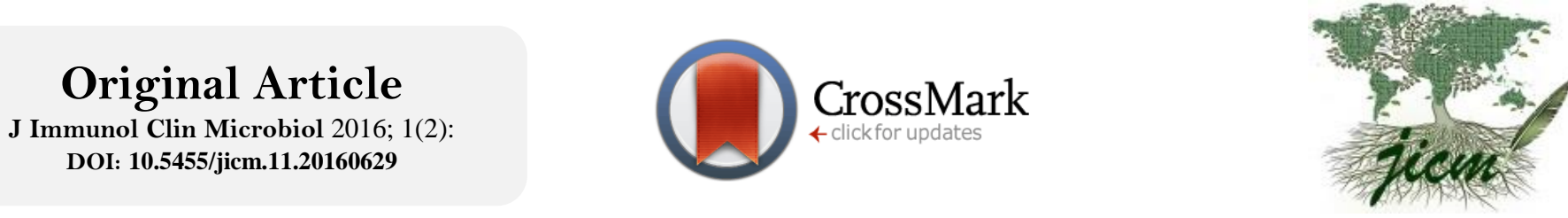

J Immunol Clin Microbiol

\title{
Distribution of the patterns in patients with positive antinuclear antibody and anti-extractable nuclear antigen
}

\author{
Keramettin Yanik $^{1 *}$, Nevzat Unal ${ }^{2}$, Asuman Birinci ${ }^{1}$, Murat Gunaydin ${ }^{3}$ \\ ${ }^{1}$ Ondokuz Mayis University, School of Medicine, Department of Medical Microbiology, Samsun, Turkey \\ ${ }^{2}$ Adana Numune Training and Research Hospital Laboratory of Microbiology, Adana, Turkey \\ ${ }^{3}$ İstanbul University, Cerrahpasa School of Medicine, Department of Medical Microbiology, İstanbul, Turkey
}

\begin{abstract}
Background: Early diagnosis of autoimmune disorders is critical in order to prevent complications, morbidity and mortality. Antinuclear antibody (ANA) tests are commonly used in support of the diagnosis of autoimmune diseases. In the present study, we aimed to compare and evaluate the ANA patterns which were determined via an IFA method for the detection of the presence of autoantibody against extractable nuclear antigens (ENA).

Material and Methods: Antinuclear antibodies were tested for a total of 5453 patients admitted to various clinics of Ondokuz Mayis University Medical Faculty. A 1:100 dilution of each serum sample was used, and the presence of ANA and staining pattern was evaluated with ANA-IFA. A total of 616 ANA-positive samples were also tested for anti-ENA using the same method.

Results: ANA tests were detected as positive in 843 samples (15.5\%). Amongst patients, 624 (74\%) were female, and 219 (26\%) were male. Anti-ENA antibodies were positive for 192 (31.2\%) of 616 which are positive for ANA and of which anti-ENA was sought. Of those, the most common-ANA patterns were detected as speckled in $144(75.0 \%)$ samples, nucleolar in 20 (10.4\%), and homogeneous in $13(6.8 \%)$ samples. The most common anti-ENA antibodies were found to be anti-SS-A in 50 samples (26.0\%), R0-52 in 39 (20.3\%), and anti-scl-70 in 34 (17.7\%) samples.

Conclusion: Findings of the present study suggested that anti-ENA antibodies do not follow a specific ANA pattern an ANA pattern isn't related to a specific anti-ENA antibody type. However, the presence of various ANA patterns may sometimes be associated with a specific disease or a syndrome. Detection of antinuclear antibodies, determination of the ANA patterns and, assessment of different ENA antibody types and interpretation of the results altogether will help the clinician significantly in the diagnosis of autoimmune diseases.
\end{abstract}

Key words: Antinuclear antibodies, indirect immune fluorescence, extractable nuclear antigen

\section{Introduction}

Autoantibodies are immunoglobulins formed against the intracellular structures of the body itself, such as nucleic acids, receptors, glycoproteins, actin, or etc. They take effect by preventing the biological functions of the target pathways such as DNA synthesis, mRNA transcription, translation, and various stages of the cell cycle.

*Corresponding Author: Keramettin Yanik. Ondokuz Mayıs University, School of Medicine, Department of Medical Microbiology, Samsun, Turkey. E-mail: drkeramettinyanik@gmail.com Received: May 25, 2016. Accepted: Jun 29, 2016 Published Online: Jul 20, 2016.
Antinuclear antibody (ANAs) is the antibody formed against the nuclear structures or cytoplasm. The presence of different ANA staining patterns in serum may indicate the presence of some autoimmune diseases such as systemic lupus erythematosus (SLE), rheumatoid arthritis (RA), or systemic sclerosis (1-2).
This is an Open Access article distributed under the terms of the Creative Commons Attribution Non-Commercial License (http://creativecommons.org/licenses/bync/4.0/) which permits unrestricted non-commercial use, distribution, and reproduction in any medium, provided the original work is properly cited. 
Currently, many different autoantibodies are used as clinical diagnostic markers, supporting the diagnosis, early signs of disease, classification criteria and they are utilized as prognostic factors as well (1-4). However, positivity can be seen in approximately $30 \%$ of healthy individuals at low titers such as $1 / 40$. Indirect fluorescent antibody technique (IFA) is the best method used for detection of ANA at HEp-2 cells as a resource of antigen. Determination of different types of autoantibodies in ANA spectrum is possible. Recently, a positivity at 1/160 dilution and above is considered significant (3-7).

Some proteins found in the nucleus of the cell can be extracted using saline, and are called extractable nuclear antigens (ENA). Among ENAs, Smith ( $\mathrm{Sm}$ ) antigen is a non-histon acidic ribonucleoprotein with low molecular weight; SS-A is a protein playing role in the process of mRNA, SS-B is a phosphoprotein playing role as a cofactor for RNA polymerase III; Scl-70 antigen is defined as DNA topoisomerase I, and Jo-1 is the histidyltRNA synthetase enzyme (8). Determination anti-ENA antibodies can play a critical role in the differential diagnosis of autoimmune disorders, and is performed using the indirect immune fluorescent (IFA) method.

In the present study, we aimed to compare and evaluate ANA patterns determined via IFA method for the detection of autoantibodies against ENAs.

\section{Material and methods}

\section{Patients and samples}

Antinuclear antibodies were investigated in the sera 5453 patients admitted to various clinics of Ondokuz May1s University Medical Faculty between October 2010 December 2012.

\section{Detection of antinuclear antibodies and subgroups}

ANA testings was performed in serum samples using the IFA method (Euroimmun, Lübeck, Germany). The presence of ANA and different staining patterns were tested following the manufacturers' recommendations. Briefly; 1:100 dilutions of serum samples were prepared, and were incubated with HEp-2 cells for 30 min at room temperature (RT). After washing, the slides were incubated for $30 \mathrm{~min}$ with goat fluorescein isothiocyanate-conjugated anti-human immunoglobulin $\mathrm{G}(\mathrm{IgG})$. After washing, the slides were examined using a
NikonOptiPhot-2 fluorescent microscope (Euroimmun, Lübeck, Germany).

\section{Detection of anti-ENA antibody types}

Of the ANA-positive samples a total of 616 were further tested for anti-ENA using the same method (Anti-ENA Profile Plusi IgG, Euroimmun, Lübeck, Germany). Nitrocellulose strips containing Sm, Scl-70, Jo-1, SSA, $\mathrm{SSB}, \mathrm{nRNP} / \mathrm{Sm}$, and a control (anti-human $\mathrm{IgG}$ ) were incubated with the buffer for $5 \mathrm{~min}$ at RT. 1:100 dilutions of serum samples were added, and were incubated for 30 min at RT. After washing, enzyme conjugate was added and incubated for $30 \mathrm{~min}$ at RT. After the addition of the stop solution, the strips were evaluated using the EUROLineScan software (Euroimmun, Lübeck, Germany).

\section{Statistical analysis}

A statistical analysis was performed using SPSS Version 15.0 (IBM, Chicago, IL, United States). Descriptive variables were presented as numbers and percentages. For the categorical variables, differences between groups and associations between the variables were analyzed using Chi Square test $(\chi 2)$. An independent sample T test was used for comparison between the groups in terms of age. The results were analyzed within a confidence interval of $95 \%$, and a $p$ value of $<0.05$ was accepted as statistically significant.

\section{Results}

ANA positivity was detected in 843 specimens tested $(15.5 \%)$. The mean age of the patients whom the sera were taken was $41.2 \pm 16.9$ in ANA-positive group and $39.9 \pm 18.2$ in ANA-negative individuals. The difference between the groups was not significant $(\mathrm{p}=0.528)$.

624 of the patients $(74 \%)$ were female, and $219(26 \%)$ were male. Anti-ENA antibodies were positive for 192 (31.2\%) samples taken from 616 specimens which were ANA positive and of which anti-ENA testing performed. Of those, the most common-ANA patterns detected were as follows speckled pattern in $144(75.0 \%)$ of the samples, nucleolar pattern in 20 of the samples (10.4\%), and homogeneous pattern in $13(6.8 \%)$ samples (Figure 1). The most common anti-ENA antibodies were: antiSS-A detected in 50 (26.0\%) samples, RO-52 detected in $39(20.3 \%)$ samples, and anti-scl-70 observed in 34 (17.7\%) samples. The distribution of anti-ENA 
antibodies according to ANA patterns are shown in Table

1 .

Table 1. The distribution of anti-ENA antibodies according to ANA patterns.

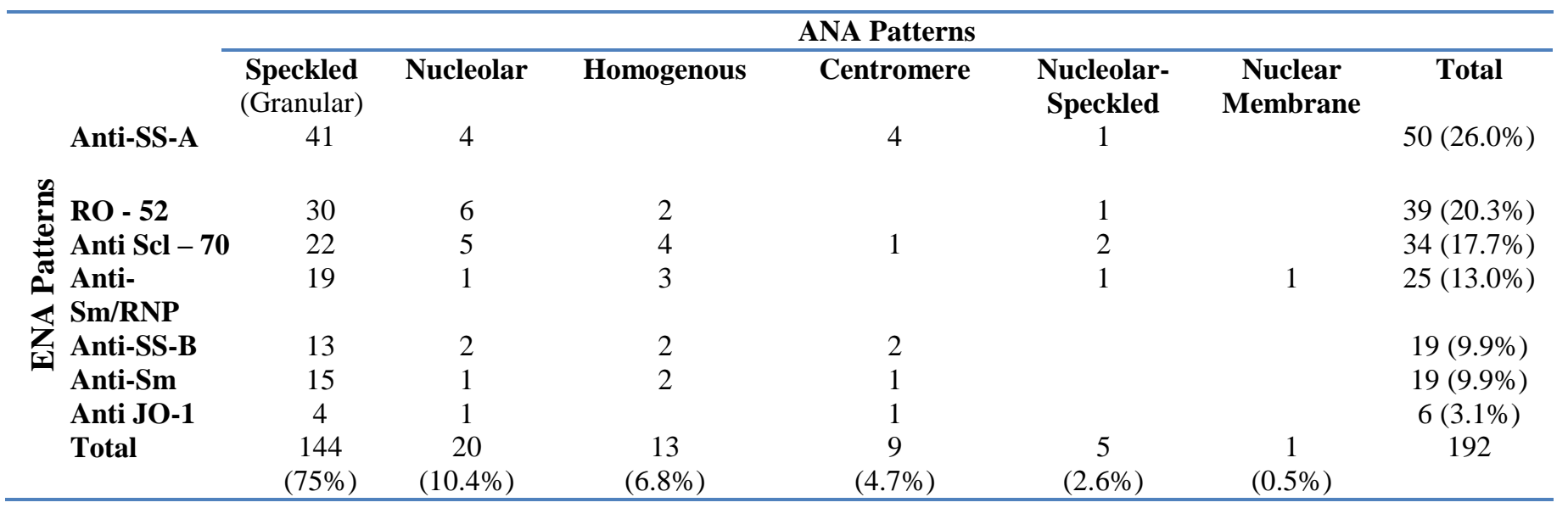
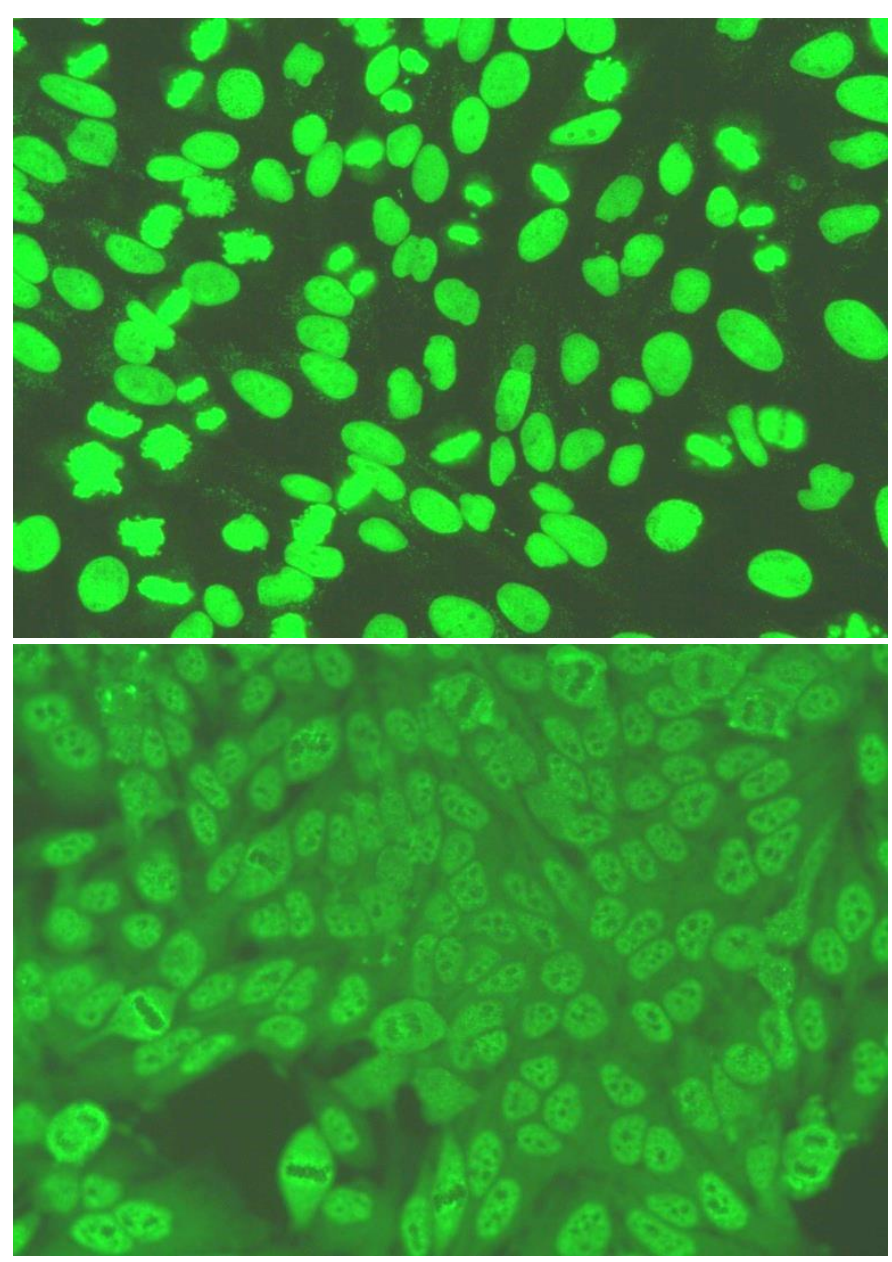

Figure 1. Examples of (upper) homogenous and (bottom) speckled staining pattern after indirect immunfluorescence antibody staining.

\section{Discussion}

Early diagnosis of the autoimmune disorders is critical in order to prevent complications, morbidity and mortality (9). Detection of ANA is commonly used to contribute to the diagnosis of autoimmune diseases. For instance, ANA is reported to be positive in more than $95 \%$ of SLE cases and mixed connective tissue diseases, in $80 \%$ of Sjögren Syndrome, as well as $40-60 \%$ of RA. ANA positivity alone is not adequate, the subgroup type of ANA such as speckled, nucleolar, or homogenous pattern should also be determined for a more specific diagnosis. This is why some subgroup patterns are known to be specific for some autoimmune disorders. For instance, nucleolar pattern can be frequently associated with scleroderma and polymyositis whereas homogenous pattern can comply with RA, SLE and drug-associated lupus.

However, it should be kept in mind that ANA can be detected as positive in elderly, in patients with carcinoma or in cytotoxic drug use cases. Moreover ANA positivity in 1:40 titer is reported to be present in $25-30 \%$ of healthy individuals. In addition, $5 \%$ of healthy individuals can reveal a titer higher than 1:160. In contrast, in some autoimmune diseases known to be highly associated with ANA positivity such as SLE, ANA results can come negative. Hence ANA results should always be evaluated together with patient history, 
clinical findings and other laboratory findings in order to provide a more accurate diagnosis (8-11).

In the present study, the IFA was used for detection of the autoimmune antibodies. Despite the fact that IFA tests using HEp-2 cells require experienced technical staff, its cost and possibility of subjective evaluation, makes the methods been reported as the most sensitive method $(8,10,11)$.

ANA positivity rates were reported to be between $8-35 \%$ in Turkey (8-11). Karakece et al. (12) found that the rate was $33.3 \%$ in a study conducted-with more than two thousand patients. In the present study, the rate was detected as $15.5 \%$ within the range of the reports from Turkey.

Mengeloglu et al. (13) stated that the most frequent ANA patterns were coarse speckled pattern $(31.2 \%)$, nucleolar pattern (18.0\%), fine speckled pattern (11.5\%), and speckled pattern $(9.7 \%)$. ANA positivity was most commonly determined in RA (8.5\%), SLE (5.9\%), and rheumatoid vasculitis (5.7\%). Özen Barut et al. (11) reported speckled pattern $(39.8 \%)$, homogenous pattern (23.9\%), and nucleolar (18.8\%) pattern in their study as the most common patterns. Their population consisted of309 ANA-positive samples. Another group, Kaklikkaya et al. (14) reported that speckled staining was the most frequent pattern which was seen in 53 (29.4\%) of 180 the ANA-positive samples they tested. Karakece et al. (12) also found that the most common patterns were speckled, nucleolar and homogenous among 755 ANA-positive samples. In the present study, the most frequent patterns were also speckled, nucleolar, and homogeneous patterns. These reports showed the same common ANA patterns in accordance with each other.

In our study, the most frequent anti-ENA antibodies detected were anti-SS-A, RO-52 and anti-scl-70. Ro-52, SS-A, anti-Sm, anti-SS-B and Scl-70, nRNP/Sm and Jo-1 was reported as the most frequent anti-ENA antibodies by Kaklikkaya et al. (14) found as. Us et al. (8) reported anti-Sm, anti-nRNP, anti-SS-A as the most common antiENA antibodies, and anti-SS-B. Further tests of ENAs can be used in the specific diagnosis of some distinct types of autoimmune disorders. However, these antibodies aren't specific to the diseases in many cases. This may be due to the polyclonal activity seen during the autoimmune disorders (8).
In the present study, the most common ANA pattern was speckled staining amongst all of the samples with speckled staining, the most common anti-ENA antibodies were detected to be anti-SS-A, Ro-52, anti-Scl-70, and anti-Sm/RNP, respectively. This distribution was in accordance with the general anti-ENA antibody frequency detected previously. This finding suggests that anti-ENA antibodies do not show a specific ANA pattern, moreover, an ANA pattern doesn't fit into a specific antiENA antibody type. However, the presence of various ANA patterns may sometimes be associated with a specific disease or a syndrome. Detection of these patterns can be used as prognostic markers for diagnosis. It is suggested that if ANA testing is to add evidence to support a diagnosis when the clinical and other findings probability is high. Because ANA testing is expensive. And also the IFAT, is the gold standard for screening and ENA tests are restricted and more expensive.

\section{Conclusion}

In conclusion, detection of ANA, distinguishing of the ANA patterns, determination of the ENA antibody types, and evaluation of all those findings together will have a significant impact on the diagnosis of autoimmune diseases.

Contributions: The authors contributed equally.

Ethics Committee Approval: Ethics Committee approval was received for this study from the ethics committee.

Informed Consent: Written informed consent was obtained from patients who participated in this study.

Peer-review: Externally peer-reviewed.

Conflict of Interest: No conflict of interest was declared by the author.

Financial Disclosure: The author declared that this study has received no financial support.

\section{References}

1. Hu J, Meng W, Zhang D, Qiu C, Hua L, Xie Q, et al. Th17relevant cytokines vary with sera of different ANA staining patterns. Int Immunopharmacol 2013; 15: 679-684.

2. Satoh M, Vázquez-Del Mercado M, Chan EK. Clinical interpretation of antinuclear antibody tests in systemic rheumatic diseases. Mod Rheumatol 2009; 19: 219-228.

3. Zafrir Y, Gilburd B, Carrasco MG, Kivity S, SánchezCastañón $\mathrm{M}$, López-Hoyos $\mathrm{M}$, et al. Evaluation of an automated chemiluminescent immunoassay kit for antinuclear antibodies in autoimmune diseases. Immunol Res 2013; 56: 451-456. 
4. Avery TY, Cruys MVD, Austen J, Stals F, Damoiseaux JGMC. Anti-nuclear antibodies in daily clinical practice: prevalence in primary, secondary, and tertiary care. Journal of immunology research 2014;1-8 doi.org/10.1155/2014/401739

5. Almeida González D, Cabrera de León A, Rodríguez Pérez Mdel C, Brito Díaz B, González Hernández A, García García $D$, et al. Efficiency of different strategies to detect autoantibodies to extractable nuclear antigens. $J$ Immunol Methods 2010; 360: 89-95.

6. Egner W. The use of laboratory tests in the diagnosis of SLE. Clin Pathol 2000; 53: 424-432.

7. Kurien BT, Scofield RH. Autoantibody determination in the diagnosis of systemic lupus erythematosus. Scand J Immunol 2006; 64: 227-235.

8. Us D, Şener B, Hasçelik G, Günalp A. Investigation of the Presence of Antibodies to Extractable Nuclear Antigens (AntiENA) by Immunoblot Techniquen in Systemic Lupus Erythematosus Patients. Mikrobiyol Bul 1997; 31: 155-163.

9. Vermeersch P, Bossuyt X. Prevalence and clinical significance of rare antinuclear antibody patterns. Autoimmun Rev 2013; 12: 998-1003.

10. Yumuk $Z$, Caliskan $S$, Gündes $S$, Willke A. Investigation of antinuclear antibodies (ANA) and techniques for detection. Türk Mikrobiyol Cem Derg. 2005; 35: 40-44.

11. Özen Barut B, Emre U, Demir AS, Ünal A, Tekin İ. Nörolojik hastaliklarda antinükleer antikor (ANA) incelemesinin önemi. Evaluation 2013; 21: 25.

12. Karakece E, Atasoy AR, Cakmak G, Tekeoglu I, Harman H, Ciftci IH. Antinuclear Antibody Positivity in a University Hospital. Turk J Immunol 2014; 2: 5-8.

13. Mengeloglu Z, Tas T, Kocoglu E, Aktas G, Karabörk S. Determination of Anti-nuclear Antibody Pattern Distribution and Clinical Relationship. Pak J Med Sci 2014; 30: 380-383.

14. Kaklıkkaya N, Akıneden A, Topbaş M, Aydın F. Determination of anti-nuclear antibody seroprevalence in adult age groups in trabzon province. Balkan Med J 2013; 30: 343344.

\section{How to cite?}

Distribution of the patterns in patients with positive antinuclear antibody and anti-extractable nuclear antigen. Yanik K, Unal N, Birinci A, Gunaydin M. J Immunol Clin Microbiol 2016; 1(2).

DOI: http://dx.doi.org/10.5455/jicm.11.20160629

Submit your next manuscript to the JICM and take full advantage of:

- Convenient online submission,

- Thorough peer review, Fast Response,

- No charges,

- Immediate publication on acceptance,

- Inclusion in Scopemed and High quality indexes,

- Research which is freely available for redistribution of the worldwide literature

To submit your manuscript, click on http://www.jiacm.com

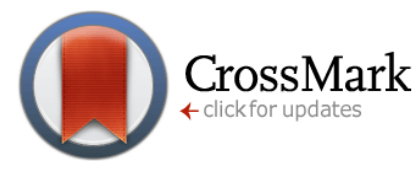

Published by The QMEL.org

International Medical Education Library

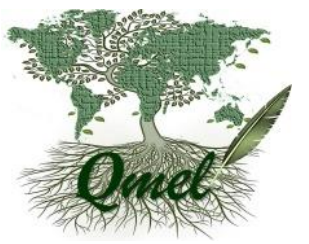

